\title{
Measuring Inequality of Opportunity in Access to Quality Basic Education: A Case Study in Florida, US
}

\author{
Lydia M. Prieto $^{1, * \mathbb{D}}$, Johannes Flacke ${ }^{1} \mathbb{D}$, Jonathan Aguero-Valverde ${ }^{2}$ \\ and Martin Van Maarseveen ${ }^{1}$ \\ 1 Faculty of Geo-Information Science and Earth Observation, University of Twente, \\ 7514 AE Enschede, The Netherlands; j.flacke@utwente.nl (J.F.); \\ m.f.a.m.vanmaarseveen@utwente.nl (M.V.M.) \\ 2 School of Civil Engineering, University of Costa Rica, San Jose, San Pedro 11501-2060, Costa Rica; \\ jonathan.aguero@ucr.ac.cr \\ * Correspondence: 1.m.prietoleon@utwente.nl or lmprietol@gmail.com; Tel.: +31(0)53-487-4444
}

Received: 24 September 2018; Accepted: 26 November 2018; Published: 29 November 2018

\begin{abstract}
Providing all children equal access to essential services, such as primary education, has been set as a priority in the Sustainable Development Goals (SDG)' agenda during the last two decades. Yet the Global Education Monitoring report in 2016 reveals that wide disparities between the rich and the poor persist in access to education of high quality. This study uses the Human Opportunity Index (HOI) to examine the equality of opportunity in access to basic education of high quality. By using enrollment and admission data from a case study in a large school district in the US in 2015/2016, this research evaluates the capacity of the HOI, in order to reveal disparities in access to school opportunities and examines how much of this inequality is explained by families' pre-determined circumstances. The way of analyzing equality is by disaggregating applications' data into circumstance groups, according to gender, geography, race/ethnicity, and other criteria. To capture the contribution of each circumstance to inequality of opportunity, the Shapley decomposition method is used. Findings show that the HOI is capable of systematically monitoring and examining existing admission policies and identifying inequality problems. Furthermore, the analysis of the contribution of each circumstance group can reveal admission criteria that have the potential to harm the educational opportunities for children. This assessment should provide valuable insights into the capability of the indicators to reveal where policy intervention is necessary and supply points of view on how policy can be improved.
\end{abstract}

Keywords: Sustainable Development Goals; inequality of opportunity; educational inequality; Human Opportunity Index; school admission; Florida

\section{Introduction}

Quality basic education has been recognized as being at the core of sustainable development. Providing all children equal access to essential services, such as clean water, improved sanitation, or primary education, has been set as a priority in the Sustainable Development Goals' (SDG) agenda over the past 15 years [1]. The ultimate goal of the 2030 Agenda for Sustainable Development is "To leave no one behind" [1]. Education was set as a priority, being considered the most vital input for every dimension of sustainable development, set to "ensure inclusive and equitable quality education and promote lifelong learning opportunities for all." [1].

Yet the Global Education Monitoring (GEM) report in 2016 [2] raises an alarm since over the past two decades social inequalities have increased, calling for urgent action for education. It reveals that 
wide disparities between the rich and the poor persist in access to education of good quality, within and between countries. Even worse, according to the World Development Report 2018, a vast number of children in the world are not benefiting from being well prepared by the schools [3]. In low-income countries, "only $36 \%$ among the poorest youth complete primary education; less than half of children complete lower secondary school, only $14 \%$ complete upper secondary education, and girls continue to lag behind boys" [4].

Equity concerns in education are addressed in target 4.5 of the SDGs, set "to eliminate gender disparities in education and ensure equal access to all levels of education and vocational training for the vulnerable" [1]. This target seeks the development of strategies for equalizing access for the groups that are most under-served, vulnerable and disadvantaged, regarding access to quality learning opportunities. These groups include persons with disabilities, indigenous peoples, ethnic minorities, children at risk, and the poor [1]. The progress of this target is measured by indicators which are still undergoing methodological development [5].

Equality of opportunity is based on the idea of giving people equal opportunity early in life, whatever their socioeconomic background, so that everybody has the same chance to be successful [6]. In his seminal contribution on equality of opportunity, Roemer [6] identifies two types of factors that determine individual outcomes: (1) factors over which individuals have control, named "efforts", i.e., autonomous choices made by individuals, such as studying hard at school; and (2) factors for which individuals cannot be held responsible, named "circumstances". Children's pre-determined circumstances are a set of personal, family or community characteristics inherited from their families and the location at birth, beyond their control [6-10].

The central argument is that in a world of equal opportunities, the circumstances should not matter. According to this, success in life should reflect a person's choices, efforts, and talents, not their background [11]. For instance, when requesting admission to a selective school, all applicants will have equal opportunity to become well educated if the only obstacle they face, all other things being equal, is passing an entrance audition or a test that reflects personal choices, efforts, and talents; or luck. It is expected that the opportunity to get admission is not influenced by children's circumstances such as gender, parental education, race, nationality, or religion.

Educational opportunities refer to "opportunities that aim to enable individuals to acquire knowledge and certain skills, and to cultivate certain capacities" [12]. Stiglitz [13] shows that, even in developed countries such as the United States and in Europe, unfairness in schooling can still be strongly perceived: "wealthy parents send their children to the best primary and high schools, and those students have a far better chance of getting into the elite universities, who also have a better chance at getting the good jobs" [13].

According to the World Inequality Report in 2018 [14], the income inequality observed in the United States is largely due to massive educational inequalities. More than fifty years ago, a landmark study led by Coleman in the US [15], "Equality of Educational Opportunity", reported that the large majority of American children attended schools that were largely segregated by race. Because neighborhoods are racially segregated, and school is a local service, this can lead to schools also divided by race. In 2015, 40.6\% of African-American students in public schools attended high-poverty schools compared to just $7.9 \%$ of white students [16].

In many states in the US, including Florida, public education is run by local towns and funded by municipalities creating a strong link between local property taxes and school funding; i.e., unequal tax bases create unequal schools [6]. Moreover, the scarcity of high-quality primary and secondary education is evident, restricted to children whose families can afford housing in wealthy neighborhoods, or who have access to private schools via tuition or scholarships [12].

The 2016 World Social Science Report [17] indicates that racial inequality has persisted for decades in the US, despite the state establishing anti-discrimination legislation to eliminate racial bias. The report informs: "A large gap-in education, income, wealth, health and justice-persists particularly between white and black Americans ... and these disparities have largely remained 
the same over the years ..." [17]. It concludes: "The life prospects of a young kid in the US is more dependent on the education and income of his parents than in any other industrial country in the world" [17].

Equity issues in SDG are currently measured using Parity Indices (PI) [2]. PI show the relative access to a service among different groups of the population. Analysis of educational disparities is currently possible by sex (female/male), location (rural/urban) and household wealth (bottom/top wealth quintile) for all education indicators that can be disaggregated. PI simply divide the indicator (e.g., primary completion rate) value for one group (e.g., women) by the value for a comparison group (e.g., men). PI has some drawbacks, such as being sensitive to low values and not representing the scale of disadvantage symmetrically around one [18]. The GEM report in 2016 addresses issues for SDG target 4.5 and calls for the inclusion of broader aspects of equity in education, beyond parity [2]. It asks for considering the contributing causes of the inequalities and giving more attention to vulnerable populations, including people with disabilities, minorities, migrants, and children whose language of instruction is not the same as the language spoken at home.

We argue that the Human Opportunity Index (HOI) [19], a tool to measure the distribution of opportunities, can be used to measure equitable access to education. The HOI, first presented by Paes de Barros and colleagues [19], carries information about the coverage rate of the service, i.e., the fraction of children who have access to educational services, but also how fairly the available places are distributed among children of different backgrounds [7]. The HOI captures the degree of inequality in multiple indicators (e.g., enrollment, achievement, admission) into one single measure, while PI requires individual analysis of each indicator.

This paper seeks to contribute to the literature by measuring the distribution of opportunities along two dimensions in the education of a young population: first, attainment, captured through enrollment profiles at schools; and second, admission, captured through student applications to schools. We further investigate the differences in distributions when we add the quality of the school. Using a case study in a large school district in the US, this study attempts to estimate the degree to which the HOI can reveal disparities in access to school opportunities for children 11-13 years old, and how much of this inequality is explained by families' pre-determined circumstances.

Consequently, the paper aims to provide an answer to the following specific questions: (1) How equal is the distribution of opportunity among groups in different circumstances? (2) How much does each circumstance contribute to the total inequality in opportunities (IOP)? (3) To what extent can HOI reveal inequalities in access to high-quality education?

Section 2 of this paper explains the problem setting, introduces the HOI methodology and prior studies using it and presents the opportunities to be assessed and the set of circumstances selected for the case study, given the data available for the school district. Section 3 describes the main opportunity gaps across individual circumstances and identifies the most important contributors. Section 4 summarizes and Section 5 concludes.

\section{Materials and Methods}

Most children in the US are assigned a public school in the attendance zone, according to the place of residence. In contrast, school choice gives parents more control over their child's education, allowing them to choose where and how their children are educated. In most school choice procedures parents are asked to submit a rank list of preferred schools. Similarly, schools have a number of available places and they rank applicants according to specific priority criteria that reflect the district's policies. A matching of students and schools determines the assignment of each student. The 'best' schools are the ones for which most parents wish to gain admission. When the number of families' expressed preferences for a school exceeds its number of available places, the admission authority uses over-subscription criteria to decide who gets the place. The student assignment problem is described by Malczewski \& Jackson [20] as an "educational resource allocation problem." 
During the past few decades, economists have been actively designing Student Assignment Plans (SAP). A few relevant examples include the Netherlands [21], Turkey [22], New York [23], Boston [24] and Chicago [25], among many others. Most of this work has been in the design and adaptation of the matching mechanisms for a school assignment. In contrast, our research focuses on the second component of the problem, studying the criteria schools establish for ranking students who apply for admission.

School priorities can be based on multiple criteria, such as having siblings, being a skilled student, having a specific socioeconomic status (based on race, income, spoken language), or living near the school, among others. It has been demonstrated that the set of rules that define admission, and the priority points assigned to students, also play an essential role in the final allocation of students [26,27]. Some schools appear to avoid certain types of students, limiting access for the most disadvantaged [28]. Some parents may face uncertainty about their own priorities when submitting preferences, due to the role of the school priorities $[29,30]$.

We investigate the student admission criteria and measure the equality of opportunities that happen when a middle-level student requests admission to a specialty school in a large school district in Florida. The analysis focuses on investigating the impact of using priorities for student admission and whether these priorities provide equal opportunities to all families. The way of analyzing equality is by disaggregating application data into circumstance groups, according to gender, geography, race/ethnicity, and other criteria. The focus is on understanding how much children's personal circumstances-such as gender, race, the location of birth, socioeconomic and demographic origin, or their family background-are considered by the schools in the admission criteria and whether this affects the access that children get to basic education of good quality.

\subsection{Case Study and Data}

The case study is the School District of Hillsborough County (SDHC), which serves the city of Tampa, Florida, and its metropolitan area. SDHC is the eighth largest school district in the US with nearly 206,000 students in about $279 \mathrm{~K}-12$ public schools [31]. More than 50,000 students attend a school through one of the district's many school choice programs. SDHC Magnet schools serve 8.5\% of the total school district population (17,700 enrolled students) in the 2015-2016 academic year.

The diverse characteristics of the SDHC enrolled population, the legacy of school desegregation issues and civil rights in black schools [32,33], and the strong association of racial distribution of students across schools and academic achievement found in previous research [34], make Hillsborough county well suited for studying equality of educational opportunities.

The focus of this study is the choice of magnet programs at middle (sixth, seventh, and eighth) school grades. Magnet schools are designed to attract pupils from various areas, offering a specialized curriculum that would draw students from across the defined geographical boundaries, based on their interest in themes such as math, music or sciences. Transportation is provided at no cost to families to almost all magnet schools. They emerged in the US as one means to eliminate, reduce, and prevent minority group isolation [35]. They tend to perform well and have a more diverse student population than neighborhood schools.

There is a consensus that more and better data are key to measuring progress towards the SDGs. In many countries data for several important indicators to measure equity in education are unavailable because those indicators require fine disaggregation among different groups in the population. Standard measures of inequality often rely on household surveys which usually underestimate the income and wealth of individuals at the top levels [14]. There is a call to host initiatives designed to integrate data from non-traditional sources, such as satellite imagery, school censuses, learning assessments and incorporating data by municipal and neighborhood levels. To overcome current limitations, we rely on the combination of data at the individual and school levels from three different data sources: school enrollment data, school accountability data, and student applications data for the SDHC academic year 2015/16. 
The first dataset contains the profiles of school enrollment for all middle schools in the district. This dataset was obtained from the National Center for Education Statistics (NCES) Common Core of Data [31], an annual national database of all public elementary and secondary schools in the US. It contains enrollment information for the academic year 2014/15 on basic socio-economic characteristics of the school population, as exhibited in Table 1, including the distribution (count of the number of students) for each subgroup on the following circumstance variables: school meal recipients (free/reduced, paid), gender (male, female), and race/ethnicity (black, hispanic, white and other).

Table 1. School enrollment data for SDHC magnet middle school programs for the 2015/2016 academic year.

\begin{tabular}{|c|c|c|c|c|c|c|c|c|c|}
\hline \multirow[b]{2}{*}{ ALT } & \multirow[b]{2}{*}{ School Name } & \multirow[b]{2}{*}{$\begin{array}{l}\text { School } \\
\text { Grade }\end{array}$} & \multirow[b]{2}{*}{$\begin{array}{l}\text { Urban } \\
\text { Locale }\end{array}$} & \multirow[b]{2}{*}{$\begin{array}{c}\text { Title I } \\
\text { School }\end{array}$} & \multirow[b]{2}{*}{$\begin{array}{c}\text { Total } \\
\text { Students }\end{array}$} & \multicolumn{2}{|c|}{ Lunch Status } & \multicolumn{2}{|c|}{ Gender } \\
\hline & & & & & & FRL & PAY & $\mathbf{M}$ & $\mathbf{F}$ \\
\hline S1 & Stewart & A & $\mathrm{CL}$ & YES & 857 & $70 \%$ & $30 \%$ & $65 \%$ & $35 \%$ \\
\hline S2 & Dowdell & $\mathrm{C}$ & SL & YES & 613 & $92 \%$ & $8 \%$ & $54 \%$ & $46 \%$ \\
\hline S3 & Sligh & $\mathrm{F}$ & $\mathrm{CL}$ & YES & 648 & $95 \%$ & $5 \%$ & $50 \%$ & $50 \%$ \\
\hline S4 & Franklin (Boys) Magnet & A & $\mathrm{CL}$ & YES & 419 & $68 \%$ & $32 \%$ & $100 \%$ & $0 \%$ \\
\hline S5 & Ferrell (Girls) Magnet & $\mathrm{A}$ & $\mathrm{CL}$ & YES & 405 & $74 \%$ & $26 \%$ & $0 \%$ & $100 \%$ \\
\hline S6 & Orange Grove Magnet & $\mathrm{A}$ & $\mathrm{CL}$ & NO & 562 & $48 \%$ & $52 \%$ & $30 \%$ & $70 \%$ \\
\hline S7 & Progress Village & $\mathrm{A}$ & SL & NO & 865 & $55 \%$ & $45 \%$ & $34 \%$ & $66 \%$ \\
\hline S8 & Roland Park K-8 Magnet & $\mathrm{A}$ & $\mathrm{CL}$ & $\mathrm{NO}$ & 763 & $42 \%$ & $58 \%$ & $52 \%$ & $48 \%$ \\
\hline S9 & Rampello K-8 & $\mathrm{A}$ & $\mathrm{CL}$ & $\mathrm{NO}$ & 766 & $45 \%$ & $55 \%$ & $49 \%$ & $51 \%$ \\
\hline S10 & Walker Magnet & $\mathrm{A}$ & RF & $\mathrm{NO}$ & 900 & $38 \%$ & $62 \%$ & $49 \%$ & $51 \%$ \\
\hline S11 & Williams & $\mathrm{A}$ & $\mathrm{CL}$ & $\mathrm{NO}$ & 798 & $38 \%$ & $62 \%$ & $52 \%$ & $48 \%$ \\
\hline \multirow[t]{3}{*}{ S12 } & Young Magnet & $\mathrm{C}$ & CL & YES & 561 & $88 \%$ & $12 \%$ & $58 \%$ & $42 \%$ \\
\hline & Total Magnet Middle & & & & 8157 & $60 \%$ & $40 \%$ & $50 \%$ & $50 \%$ \\
\hline & Total Enrolled Popul & & & & 207,469 & & & & \\
\hline
\end{tabular}

Note: ALT: Alternative Code; NCES Urban Locale: Citi, Large (CL); Suburban, Large (SL); Rural, Fringe (RF); Lunch Status: Free/Reduced (FRL), Paid (PAY); Student Gender: Male (M), Female (F). FDOE School Grading Scale: $\mathrm{A}=62 \%$ of points or greater, $\mathrm{B}=54 \%$ to $61 \%$ of points, $\mathrm{C}=41 \%$ to $53 \%$ of points, $\mathrm{D}=32 \%$ to $40 \%$ of points, $\mathrm{F}=31 \%$ of points or less.

The second dataset comprises school accountability data that gives information about the quality of education delivered for each school, collected by the Florida Department of Education (FDOE) for the year 2014/15. This dataset holds information about student performance on statewide standardized assessments [36]. School quality is measured by the school grades, a way to measure the performance of a school. The school grade formula includes achievement components (English language, arts, mathematics, science, and social studies), learning gains, graduation rates, and college and career acceleration components. This school grading system conveys the achievement level of Florida's schools and reflects student outcomes, and therefore can be used to understand how well each school is serving its students [36].

The third dataset consists of geocoded applications to magnet middle schools in SDHC, for the academic year 2015-2016. This geographic dataset contains secure and anonymized applicant's records including preferred schools, home location, and demographic details of the applicants. School-level data provides information about the characteristics of available school programs and geographic boundaries of school service areas. Table 2 shows simple information about the SDHC magnet middle school dataset including 7798 ranked choices made by 3723 applicants to 12 magnet middle school programs. Applicants rank up to three schools in the application. The first ranked school is used for this study, as it captures an applicant's most desired choice. The number of categories for each circumstance variable was reduced to four or fewer, in order to reduce the number of types with zero or few observations in the dataset. 
Table 2. SDHC magnet middle enrolled population and applications by race/ethnicity for the 2015-2016 academic year.

\begin{tabular}{|c|c|c|c|c|c|c|c|c|c|c|c|c|c|}
\hline \multirow[t]{2}{*}{ ALT } & \multirow[t]{2}{*}{ School } & \multirow[t]{2}{*}{ Program } & \multirow{2}{*}{$\begin{array}{l}\text { FDOE } \\
\text { Theme }\end{array}$} & \multirow{2}{*}{$\begin{array}{c}\begin{array}{c}\text { Total } \\
\text { Enrolled }\end{array} \\
\text { Population }\end{array}$} & \multicolumn{4}{|c|}{ Enrolled Population } & \multirow{2}{*}{$\begin{array}{c}\begin{array}{c}\text { Total All } \\
\text { Ranked }\end{array} \\
\text { Applications } \\
\end{array}$} & \multicolumn{4}{|c|}{ All Ranked Applications } \\
\hline & & & & & BLA & WHI & HIS & XOT & & BLA & WHI & HIS & XOT \\
\hline S1 & Stewart & Math/Science/Technology & MAT & 857 & $34 \%$ & $24 \%$ & $35 \%$ & $7 \%$ & 1011 & $27 \%$ & $33 \%$ & $27 \%$ & $13 \%$ \\
\hline S2 & Dowdell & Environmental Studies & OTH & 613 & $28 \%$ & $19 \%$ & $49 \%$ & $4 \%$ & 283 & $27 \%$ & $36 \%$ & $29 \%$ & $8 \%$ \\
\hline S3 & Sligh & Health Professions & OTH & 648 & $76 \%$ & $4 \%$ & $16 \%$ & $4 \%$ & 339 & $38 \%$ & $32 \%$ & $18 \%$ & $12 \%$ \\
\hline S4 & Franklin (Boys) Magnet & Boys Preparatory Academy & OTH & 419 & $42 \%$ & $26 \%$ & $24 \%$ & $8 \%$ & 480 & $44 \%$ & $25 \%$ & $23 \%$ & $8 \%$ \\
\hline S5 & Ferrell (Girls) Magnet & Girls Preparatory Academy & OTH & 405 & $42 \%$ & $24 \%$ & $26 \%$ & $8 \%$ & 581 & $43 \%$ & $28 \%$ & $19 \%$ & $10 \%$ \\
\hline S6 & Orange Grove Magnet & Visual/Performing/Arts & ART & 562 & $31 \%$ & $33 \%$ & $30 \%$ & $6 \%$ & 1008 & $46 \%$ & $26 \%$ & $20 \%$ & $8 \%$ \\
\hline S7 & Progress Village & Visual/Performing/Comm. Arts & ART & 865 & $29 \%$ & $36 \%$ & $28 \%$ & $7 \%$ & 861 & $32 \%$ & $31 \%$ & $28 \%$ & $9 \%$ \\
\hline S8 & Roland Park K-8 Magnet & International Baccalaureate & IB & 763 & $28 \%$ & $29 \%$ & $27 \%$ & $16 \%$ & 563 & $22 \%$ & $33 \%$ & $24 \%$ & $21 \%$ \\
\hline S9 & Rampello Downtown K-8 & Cultural Arts \& Humanities & OTH & 766 & $32 \%$ & $34 \%$ & $29 \%$ & $5 \%$ & 210 & $37 \%$ & $30 \%$ & $25 \%$ & $8 \%$ \\
\hline S10 & Walker Magnet & International Baccalaureate & IB & 900 & $12 \%$ & $42 \%$ & $31 \%$ & $15 \%$ & 764 & $13 \%$ & $23 \%$ & $42 \%$ & $22 \%$ \\
\hline S11 & Williams & International Baccalaureate & IB & 798 & $29 \%$ & $23 \%$ & $19 \%$ & $29 \%$ & 779 & $33 \%$ & $18 \%$ & $22 \%$ & $27 \%$ \\
\hline S12 & Young Magnet & Creative Science Centre & MAT & 561 & $52 \%$ & $13 \%$ & $30 \%$ & $5 \%$ & 919 & $48 \%$ & $25 \%$ & $18 \%$ & $9 \%$ \\
\hline \multirow{2}{*}{\multicolumn{2}{|c|}{ Total magnet middle schools }} & & & 8157 & 2816 & 2171 & 2355 & 815 & 7798 & 2692 & 1911 & 2141 & 1054 \\
\hline & & & & & $34 \%$ & $27 \%$ & $29 \%$ & $10 \%$ & & $34 \%$ & $25 \%$ & $27 \%$ & $14 \%$ \\
\hline \multirow{2}{*}{\multicolumn{2}{|c|}{ Total enrolled population }} & & & 207,469 & 44,402 & 74,336 & 71,971 & 16,760 & & & & & \\
\hline & & & & & $21 \%$ & $36 \%$ & $35 \%$ & $8 \%$ & & & & & \\
\hline
\end{tabular}

Note. ALT: Alternative code; Theme Specialty: MAT (Sciences/Math), ART (Performing Arts), IB (International Baccalaureate), OTH (Other Theme Specialty); Race/Ethnicity: BLA (Black),

WHI (White), HIS (Hispanic), XOT (Other Race/Ethnicity). 


\subsection{Choice of Opportunities}

Common measures of education output are coverage rates for school attendance, school enrollment, and timely school completion [37]. Education quality is another key consideration in defining access [38]. The latter is significant because not all schools provide the same quality of instruction [39], some schools may be better than others at helping students learn. Substantial research suggests that school quality highly affects student learning [40].

Indicators of access to education are considered as opportunities available in the children's place of residence, necessary to achieve their human potential [8]. The two indicators of access to education used in this paper are defined as follows: (1) whether a child is enrolled in a school of high-quality; (2) whether a child receives an offer for admission to a school of high-quality. In this context, young children 11 to 13 years of age enrolled/admitted to a high-quality school have the opportunity to be well-educated.

The school letter grade is used to measure the school quality, assigned by the FDOE of A, B, C, $\mathrm{D}$, or F. HOI requires to dichotomize the output (dependent) variable. Therefore, in this work schools are coded as "high-quality" when they are ranked with A or B scores, and "poor-quality" when the schools are ranked with C, D, or F scores.

\subsection{Choice of Circumstances}

Following Roemer's classification [6], our circumstances are variables specific to the child, including the demographic and socioeconomic status of the household, geographic settings of the household, and the characteristics of the attendance area school. Table 3 shows the set of circumstances considered for this study.

The choice of the circumstances involves subjective judgment. It reflects the priority criteria used for student admission to magnet middle schools at SDHC for the 2015/2016 academic year; this list was supplemented with a common set of variables used by prior studies in educational opportunity $[15,39,41,42]$, and constrained by the data available for the school district for the case study. Note that the assessment of IOP is conditional on observed circumstances, and the indexes change if a different set of circumstances is considered [8].

SDHC utilizes a race-neutral weighted lottery process for student admission. Applicants receive the applicable weight (points) for each of the lottery parameters. The weight only applies to those designated with 'yes' in the column 'admission criteria' in Table 3. Points are accumulated for all criteria and function as 'tickets' for the lottery. The more points an applicant gets, the greater the chance he/she will receive an offer. Since the selection is random, the applied weight does not guarantee admission.

Children who qualify for free and reduced-price lunch (FRL) program are considered low-income; this variable is used as a proxy for the socioeconomic status (SES) of the student. The variable female is a dichotomous variable coded 1 if the student was female and 0 if male. Race/ethnicity was encoded into four categories: black, hispanic, white and other. The reference category is white. Distance from home to school was calculated using the road network. Children with disability in Florida are identified as recipients of exceptional student education, coded 1 when they have any kind of disability and 0 if none. The language spoken at home was encoded as a dichotomous variable coded 1 if English is spoken at home and 0 if any other language is spoken at home.

The last row captures the academic status of the student's assigned attendance area school. A weight (points) is applied for each year a school has not met the accountability factor. In practical terms, this lottery parameter is used to give priority to children residing in an attendance area with high numbers of economically disadvantaged students (assigned to Title I schools, of the Elementary and Secondary Education Act (ESEA)), who are failing, or most at risk of failing, to meet state student academic achievement standards. 
Table 3. Choice of circumstances for access to high-quality education.

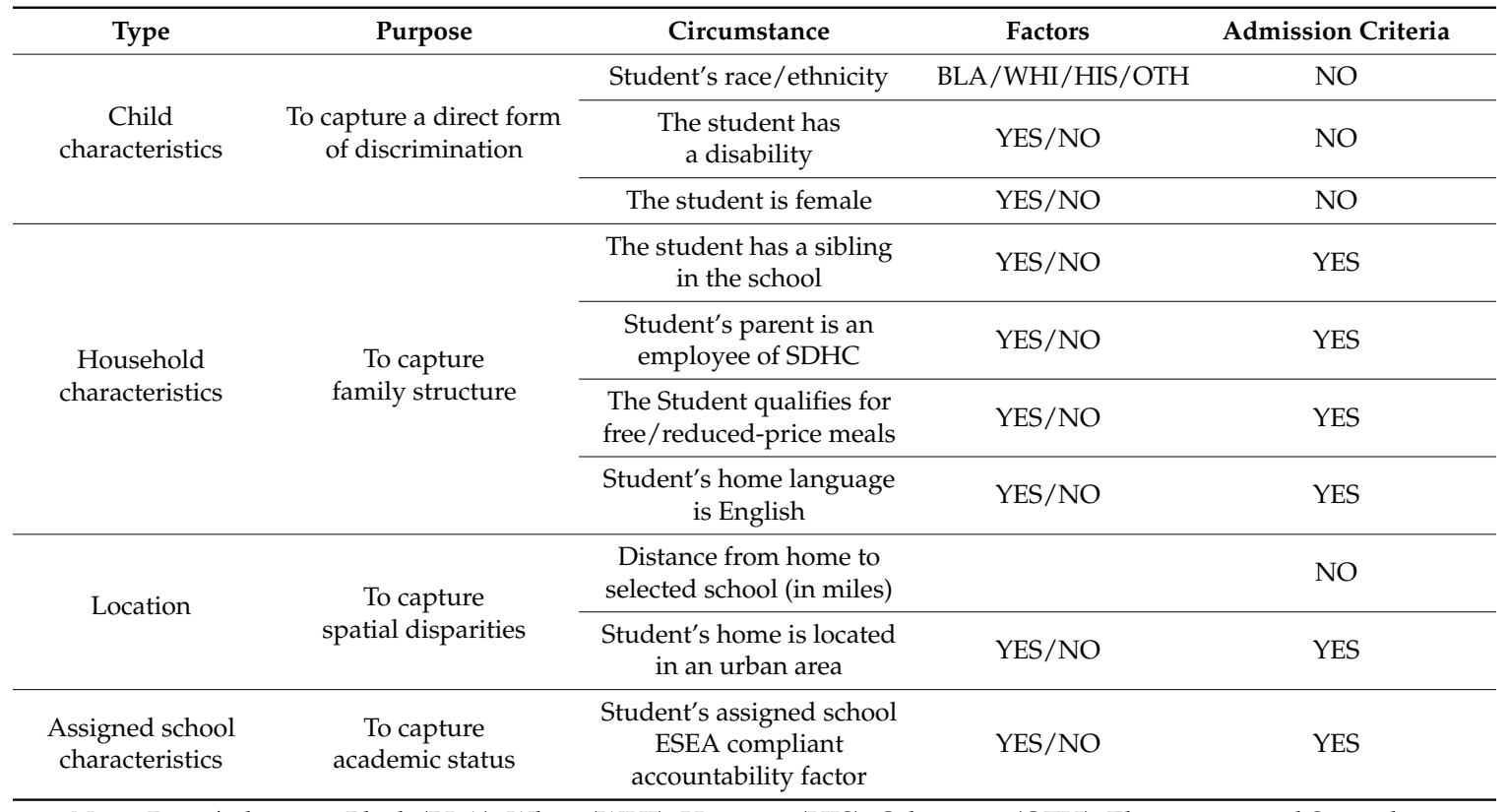

Note: Race/ethnicity: Black (BLA), White (WHI), Hispanic (HIS), Other race (OTH); Elementary and Secondary Education Act (ESEA). Note that in the admission criteria, SDHC elementary magnet students applying for middle magnet schools are identified and a weight is applied for this parameter. However, this information was not available in the dataset.

\subsection{Methods}

This section introduces the methodology of HOI following Chapter 2 of Debalen et al. [8] and applied to IOP for education. HOI was first introduced by Paes de Barros et al. [19,43] and Molinas et al. [38]. A complete discussion can be found in Paes de Barros et al. [44].

\subsubsection{Opportunity Measures: To be Enrolled in a High-Quality School}

The coverage $C$ is the percentage of individuals that have access to the opportunity. The Dissimilarity Index (D-index) $D$ measures the dissimilarity in access to high-quality education for groups defined by circumstance characteristics (e.g., gender, race/ethnicity, location, etc.) compared with the overall coverage rate $C$ of the population as a whole. It is widely used in sociology and applied to dichotomous outcomes.

$$
D=\frac{1}{2 C} \sum_{i=1}^{n} w_{i}\left|C-C_{k}\right|
$$

where $n$ is the number of circumstance groups. $C_{i}$ is the coverage of the circumstance group $i . w_{i}$ is the share of group $i$ in the total population. $D$ ranges from 0 to 1 ; in a situation of perfect equality of opportunity $D$ will be zero. The greater the variation, the higher the IOP.

The HOI is a measure of the coverage rate of an opportunity, discounted by inequality in the distribution across circumstance groups.

$$
H O I=(1-D) \times C
$$

The HOI tracks cover rates and cover gaps for access to key services among children. The HOI ranges from 0 (high inequality) to 100 (universal access). HOI increases with overall coverage and decreases with the differences in coverage among circumstance groups. 


\subsubsection{Opportunity Measures: To Get an Offer from a High-Quality School}

For the opportunity to get an offer from a high-quality school, the regression approach is used. Assume that there is a random sample of the population of children with information on whether child $i$ has or doesn't have access to high-quality education $\left(I_{i}=1\right.$ if the child has access and $I_{i}=0$ otherwise) and a vector of variables indicating his/her circumstances (e.g., gender, race/ethnicity, location, etc.), $X_{i}=X_{1 i}, X_{2 i}, \ldots, X_{m i}$. All children having the same set of circumstances are said to be of the same group type.

In this case, the inequality measures are calculated following six steps [45]. The first step is to estimate a logistic regression model on whether a child $i$ has access to high-quality education, as a function of his or her personal $m$ circumstances, using the maximum likelihood method.

$$
\operatorname{Ln}\left(\frac{P\left(I=1 \mid x_{1}, \ldots, x_{m}\right)}{1-P\left(I=1 \mid x_{1}, \ldots, x_{m}\right)}\right)=\sum_{k=1}^{m} \beta_{k}\left(X_{k}\right)
$$

From the estimation of this logistic regression (1), the coefficient estimates $\hat{\beta}_{k}$ are obtained. The second step is to obtain for each child, the predicted probability of access to high-quality education $\hat{p}_{i}$, based on the predicted relationship $\hat{\beta}_{k}$ and the vector of their circumstances $X_{k i}$.

$$
\hat{p}_{i}=\frac{\operatorname{Exp}\left(\hat{\beta}_{0}+\sum_{k=1}^{m} X_{k i} \hat{\beta}_{k}\right)}{1+\operatorname{Exp}\left(\hat{\beta}_{0}+\sum_{k=1}^{m} X_{k i} \hat{\beta}_{k}\right)}
$$

In step 3 the computation of the overall coverage rate for the service $C$ follow. The coverage rate summarizes information on what fraction of the population has access to a particular opportunity.

$$
C=\sum_{i=1}^{n} w_{i} \hat{p}_{i}, \text { where } n \text { is the total population and } w_{i}=\frac{1}{n} \text { or some sampling weights; }
$$

In step 4 the Dissimilarity Index (D-index) $\hat{D}$, is calculated.

$$
\hat{D}=\frac{1}{2 C} \sum_{i=1}^{n} w_{i}\left|\hat{p}_{i}-C\right|
$$

In step 5 , the computation of the penalty $P$ for inequality is obtained. $P$ refers to access to the service that was allocated unfairly.

$$
P=C \times \hat{D}
$$

The last step is to compute the HOI, discounting a penalty for improperly allocated opportunities from the overall coverage rate $C$.

$$
H O I=C-P
$$

The hoi module [45] in Stata Version 14.2. was used for the estimations. The iop module [46,47] in Stata can also be used to calculate IOP.

\subsubsection{Determinants of Inequality: To Get an Offer from a High-Quality School}

To capture the contribution of each circumstance to IOP, the Shapley decomposition method is used [48]. This procedure calculates the marginal impact of each of the factors as they are subtracted from the calculations, and then averages these marginal effects over all the possible elimination sequences [48]. The impact of adding a set of circumstances $A$ is computed as follows:

$$
D_{A}=\sum_{S \subseteq N\{A\}} \frac{|s| !(n-|s|-1) !}{n !}[D(S \cup\{A\})-D(S)]
$$


where $N$ is the set of all circumstances; $n$ is the subset of variables; $S$ is a subset of $N$ that does not contain the particular circumstance $A ; D(S)$ is the D-index estimated with the set of circumstances $S$; $D(S \cup\{A\})$ is the $\mathrm{D}$-index calculated with set of circumstances $S$ and circumstance $A$. The contribution of a set of circumstances $A$ to the inequality index is defined as:

$$
M_{A}=\frac{D_{A}}{D(N)} ; \text { where } \sum_{i \in N} M_{i}=1
$$

See [48] for further methodological details. The hoishapley module [49] in Stata version 14.2. was used to compute the decomposition of HOI.

\subsection{Prior Studies in Educational Inequalities}

There is already a large volume of theory and applied literature on the measurement of equity and on equality of opportunity. Much of this work is focused on economic opportunities but later applied to health and education. See Roemer and Trannoy [50] and Ramos and Van De Gaer [51] for recent literature reviews.

Early work measuring equality of opportunity in education focused on quality (achievement). Ferreira and Gignoux [39] propose two measures of educational opportunity: one, a measure of educational achievement, defined as the variance or standard deviation of the OECD's Program of International Student Assessment (PISA) test scores; second, a measure of educational opportunity, calculated as the share of the variance in test scores that is explained by pre-determined circumstances in a linear regression. Using the enrollment-age profiles and the standardized PISA test scores 2006 applied for Turkey, the same authors report large differences by student's gender, spatial location and family background such as parental education and father's occupation [42]. Schlicht, Stadelmann, and Freitag [52] applied hierarchical regression models using data from the 2006 PISA from the European Union (EU) countries to analyze the impact of education policy conditions on the relationship between children's social background and their educational performance (achievement in mathematics). Similarly, using data from nine US states that participated in the 1999 TIMSS test, Schmidt and colleges [53] explore the extent to which students in different schools have an equal opportunity to learn mathematics.

Among the multiple measures that are available, this study focused on the HOI. HOI is a statistical tool that has been applied over the world for measuring the extent of equality of opportunity in multiple dimensions, such as health, household infrastructure, education, and income, in a given country or region as part of a diagnostic approach. Diagnostic studies for regions include Latin America and the Caribbean [38], Sub Saharan Africa [8], and the Middle East and North Africa [9]. Country-specific applications of the HOI are abundant, some examples include Peru [54], Brazil [55], Colombia [10], Egypt [56] and Vietnam [57]. Country-specific analysis of educational inequalities based on HOI is found for Albania [58], Liberia [59], Turkey [42], and Uruguay [60], among many others.

Worldwide, the Global Education Monitoring Report (GEM) tracks progress towards SDG goal 4, based on the World Inequality Database on Education (WIDE) [61], which compiles data from surveys for over 160 countries. WIDE reports indicators for access, completion, and learning, according to factors associated with inequality such as gender, wealth, location and ethnicity. Complementary, the Handbook on Measuring Equity in Education [62], not only summarizes the most relevant literature on equity but also provides a conceptual framework and methodological guidance in the construction, visualization, and interpretation of the indicators. It discusses five concepts for measuring equity in education: meritocracy, minimum standards, impartially, equality of condition and redistribution [62]. According to this classification, the HOI is considered a combined measure of minimum standards (the access rate) and impartiality (the dissimilarity index). 


\section{Results}

\subsection{Opportunity Measures: To Be Enrolled in a High-Quality School}

Table 4 shows the distribution of educational opportunities at SDHC, by considering how the enrollment profile varies by population sub-groups given the circumstance variables. The first measure is the general coverage $C$ (shown in bold characters), i.e., the percentage of children that have access to the opportunity. Being enrolled in a high-quality school is a privilege for $77.7 \%$ of the magnet school population at SDHC, a luxury when it is compared with the $53.5 \%$ of all public students at middle level in the District, and with the $54.4 \%$ of all public students at middle level in the State of Florida, suggesting that magnet schools provide higher opportunities for access to high quality public education at lower secondary level.

Table 4. Opportunity to be enrolled in a high-quality magnet middle school at SDHC.

\begin{tabular}{|c|c|c|c|c|c|c|}
\hline Circumstance Variables & $\begin{array}{l}\text { All Magnet MIS } \\
\text { Population }\end{array}$ & $\begin{array}{l}\text { Enrolled in } \\
\text { High-Quality }\end{array}$ & $C_{k}$ & $\alpha_{k}$ & $D$ & HOI \\
\hline \multicolumn{7}{|l|}{ Student Lunch Status } \\
\hline Pay lunch & 3247 & 3099 & 95.4 & 39.8 & & \\
\hline Free/reduced lunch & 4910 & 3236 & 65.9 & 60.2 & & \\
\hline Subtotal & 8157 & 6335 & 77.7 & 100.0 & 9.11 & 70.58 \\
\hline \multicolumn{7}{|l|}{ Student Gender } \\
\hline Male & 4054 & 3073 & 75.8 & 49.7 & & \\
\hline Female & 4103 & 3262 & 79.5 & 50.3 & & \\
\hline Subtotal & 8157 & 6335 & 77.7 & 100.0 & 1.19 & 76.74 \\
\hline \multicolumn{7}{|l|}{ Student Race/Ethnicity } \\
\hline Black & 2816 & 1865 & 66.2 & 34.5 & & \\
\hline Hispanic & 2355 & 1779 & 75.5 & 28.9 & & \\
\hline Other & 815 & 740 & 90.8 & 10.0 & & \\
\hline White & 2171 & 1951 & 89.9 & 26.6 & & \\
\hline Subtotal & 8157 & 6335 & 77.7 & 100.0 & 5.87 & 73.10 \\
\hline
\end{tabular}

Note: $C$ : Overall coverage rate of the service (77.7) for all groups; $C_{k}$ : coverage rate of the circumstance group $k$; $\alpha_{\mathrm{k}}$ : share of group $k$ in total population; $D$ : dissimilarity index; HOI: human opportunity index.

According to Roemer [6], equality of opportunity is achieved when the distributions of outcomes are identical across social groups defined by the circumstances. The IOP idea is to look at what is happening with the gaps across the population of different socio-economic backgrounds. For that, all groups of circumstances with rates of coverage below the average are identified. We refer to these groups as "vulnerable" to loss of educational opportunity (shown with a grey background in Table 4).

There are no significant disparities in gender. The share of both, the female and male population are close to the overall coverage, and hence the dissimilarity index and the penalty are close to zero. The access rate is roughly the same as the HOI, telling that the distribution of opportunities for both genders is equitable.

In contrast, a significant gap in access across meal recipients can be observed. About $66 \%$ of students eligible for free and reduced-price meals-representing the low socioeconomic status students-are in disadvantage, and hence identified as vulnerable, with a group coverage below the overall coverage $(77.7 \%)$. To ensure equitable coverage of education across low-income and high-income families, about $9 \%$ of available services would need to be reallocated. This disparity among the social groups is captured by a high D-index of 9.1 which generates the HOI of 70.58, the lowest among the considered circumstance groups. HOI must lie between 0 and 100 percent, since the HOI is lower than the coverage rate of the opportunity, and the difference between the two represents the "penalty" for an unequal distribution.

A moderate gap across the population of different race/ethnicity background is also perceived, suggesting that opportunities are unequally distributed. When considering each of the race/ethnic 
groups, one vulnerable group can be observed: black (66.2\%), whose share is below the overall coverage $(77.7 \%)$. The share for hispanic children $(75.5 \%)$ is close to the average. For whites and other race/ethnic groups, the coverage is higher than the overall coverage, suggesting disparities in the opportunities work in their favor. The D-index of 5.8 displays the share of total enrollments that are "misallocated", generating an HOI of 73.

Note that this approach has methodological shortcomings since multiple circumstance variables are related to each other. By computing the IOP one by one, it is overestimated to some extent due to double-counting; e.g., being low-income has a negative effect; being women has a negative effect and being a low-income woman is worse than the two effects summed up. To improve accuracy in the IOP index, information at a more disaggregated level is required. The analysis in the next section overcomes this limitation.

\subsection{Opportunity Measures: To Get an Offer from a High-Quality School}

Table 5 shows the model estimates for the opportunity to get an offer in the school of any quality (left) and a school of high-quality (right). Given a large dataset, equality of opportunity would imply that the access to high-quality education should be independently distributed of the circumstances [42]. In statistical terms, in an equal opportunity society, there is no statistically significant association between circumstances and important life outcomes. Note that in some cases the IOP is underestimated due to the omission of the interaction effects. Hence the estimated D-index is the lower bound of inequalities, and the estimated HOI is the upper bound.

For the admission to high-quality schools, student disability status, having a sibling in the school, being female and speaking the English language at home is not statistically significant in explaining the admission to SDHC magnet middle schools in 2015-2016. Non-significant coefficients and coefficients with the unexpected sign are kept in the estimation [8]. For both models (any-quality vs. high-quality), the geography variables (distance from home and student's home located in an urban area) are significant. A decrease of 5.6 in the log-odds of getting admission is expected when the applicant lives in an urban area-instead of a rural area-for a school of any quality, and a decrease of 4.4 for a school of high-quality.

Overall, in 27 out of 33 OECD countries including the US, the location of the family's residence and its proximity to the school is the principal criterion for assigning schools to students for lower and higher secondary schools [63]. In contrast, our analysis reveals that distance is not an important criterion for student assignment at magnet schools at SDHC. In fact, at SDHC magnet middle schools, for every additional mile in the distance from home to school, a 1.06 increase in the log-odds of getting the admission is expected, holding all other independent variables constant. The sign and magnitude of this coefficient are unexpected but clearly explained by the fact that magnet children are transported for free over large distances across the district.

Living in a place where the attendance area school is a Title I school and having a parent who is an employee at the school district are both statistically significant variables for the admission to schools of any and high quality. As explained before, at SDHC priority is given to families who reside in a public-school attendance area with high numbers of low-income students. This mechanism provides students living in poverty, who are in the greatest educational need of those services, with the extra educational supports they need to achieve academically. This mechanism might be used by the school district to overcome the deprived circumstance of the child given by his/her current place of residence.

Two differences are relevant between the estimates of any-quality vs. high-quality schools: First, if the student has a low socioeconomic status, the log-odds of getting an offer in a high-quality school are decreased by 5.29 . Second, if the student's race/ethnicity is black, the log-odds of getting an offer in a high-quality school are decreased by 3.06 and if he/she is a latino student, the log-odds are increased by 2.40 , both of them in comparison with the chances for white students, the reference category. 
Table 5. Model estimates for the opportunity to get an offer to an SDHC magnet middle school.

\begin{tabular}{|c|c|c|c|c|c|c|c|c|}
\hline \multirow[b]{2}{*}{ Model Variables } & \multicolumn{4}{|c|}{ School of Any Quality } & \multicolumn{4}{|c|}{ School of High-Quality } \\
\hline & Coef. & $\begin{array}{l}\text { Robust } \\
\text { Std. Error }\end{array}$ & $\mathbf{z}$ & $\mathbf{P}>\mathbf{z}$ & Coef. & $\begin{array}{l}\text { Robust } \\
\text { Std. Error }\end{array}$ & $\mathbf{z}$ & $\mathbf{P}>\mathrm{z}$ \\
\hline The student qualifies for FRL & -0.1068 & 0.0928 & -1.15 & 0.250 & -0.4526 & 0.0855 & -5.29 & 0.000 \\
\hline Student's race/ethnicity is black & -0.0058 & 0.1039 & -0.06 & 0.955 & -0.2914 & 0.0952 & -3.06 & 0.002 \\
\hline Student's race/ethnicity is hispanic & 0.3314 & 0.1327 & 2.50 & 0.012 & 0.2914 & 0.1213 & 2.40 & 0.016 \\
\hline Student's race/ethnicity is other race & 0.1974 & 0.2030 & 0.97 & 0.331 & 0.1996 & 0.1819 & 1.10 & 0.273 \\
\hline The Student has a disability & -0.0120 & 0.0827 & -0.14 & 0.885 & 0.0742 & 0.0758 & 0.98 & 0.327 \\
\hline Student is female & -0.1990 & 0.0781 & -2.55 & 0.011 & -0.0065 & 0.0715 & -0.09 & 0.927 \\
\hline The student has a sibling & 0.1273 & 0.0860 & 1.48 & 0.139 & 0.1296 & 0.0776 & 1.67 & 0.095 \\
\hline Student's parent is an employee & 1.4379 & 0.2759 & 5.21 & 0.000 & 1.3297 & 0.2180 & 6.10 & 0.000 \\
\hline Student's home language is English & 0.1902 & 0.1472 & 1.29 & 0.196 & 0.2296 & 0.1331 & 1.73 & 0.084 \\
\hline Student's assigned school is Title I & 0.0983 & 0.0088 & 11.22 & 0.000 & 0.0727 & 0.0076 & 9.62 & 0.000 \\
\hline Distance from home to school & 0.9206 & 0.2743 & 3.36 & 0.001 & 1.0612 & 0.2631 & 4.03 & 0.000 \\
\hline Student's home is located in an urban area & -0.0116 & 0.0021 & -5.64 & 0.000 & -0.0088 & 0.0020 & -4.40 & 0.000 \\
\hline Constant & -0.7160 & 0.3420 & -2.09 & 0.036 & -1.0359 & 0.3212 & -3.23 & 0.001 \\
\hline \multicolumn{9}{|l|}{ Model Statistics } \\
\hline Log Likelihood & $\mathrm{Ll}$ & -1984.97 & & & $\mathrm{Ll}$ & -2276.72 & & \\
\hline Chi-square & chi2 & 205.93 & & & chi2 & 258.87 & & \\
\hline Akaike Information Criterion & Aic & 3995.94 & & & Aic & 4579.43 & & \\
\hline Bayesian Information Criterion & Bic & 4076.83 & & & Bic & 4660.32 & & \\
\hline Degree of Freedom & Df & 13 & & & Df & 13 & & \\
\hline
\end{tabular}

Note: Coef.: Raw coefficient; z: $\mathrm{z}$-score for test of $\mathrm{b}=0 ; \mathrm{P}>\mathrm{z}$ : $p$-value for $\mathrm{z}$-test; Std. Err: The standard errors associated with the coefficients. The significance is at the $95 \%$ confidence level. 
The top part of Table 6 shows the measures of equality of opportunity for the admission to schools. The rate of overall coverage is affected by the quality component; while for any-quality schools it is close to $75 \%$, the coverage rate lowers to $64 \%$ for high-quality schools. The D-index indicates the distance between the distribution of the opportunities and the distribution of the population across circumstance groups. The greater the variation, the higher the IOP.

Table 6. Inequality Measures and contribution of circumstances to IOP for the opportunity of getting an offer to an SDHC magnet middle school.

\begin{tabular}{ccccc}
\hline & \multicolumn{2}{c}{ School of Any Quality } & \multicolumn{2}{c}{ School of High-Quality } \\
\hline & Values & Std. Error & Values & Std. Error \\
\hline Inequality Measures & & & & \\
Coverage (C) & 74.4561 & 0.6906 & 64.1418 & 0.7540 \\
Dissimilarity Index (D) & 5.9482 & 1.5901 & 8.5719 & 2.0364 \\
Human Opportunity Index (HOI) & 70.0273 & 0.8179 & 58.6436 & 0.8565 \\
\hline Shapley Decomposition of D-index & & & & \\
The student qualifies for FRL & 5.53 & & 23.15 & \\
Student's race/ethnicity is black & 5.81 & & 15.74 & \\
Student's race/ethnicity is hispanic & 3.86 & & 1.06 & \\
Student's race/ethnicity is other race & 0.78 & & 4.00 & \\
The student has a disability & 1.65 & & 0.50 & \\
The student is female & 5.56 & & 9.61 & \\
The student has a sibling & 1.79 & & 0.79 \\
Student's parent is an employee & 10.31 & & 34.92 \\
Student's home language is English & 0.90 & & 1.61 & \\
Student's assigned school is a Title-I school & 56.84 & & 3.81 & \\
Distance from home to school & 1.05 & & & \\
Student's home is located in an urban area & 5.93 & & & \\
\hline
\end{tabular}

The D-index, similarly, reveals more disparities in the distribution of the opportunities when the quality of the school is considered. Quantitatively, the D-index reveals that in SDHC $8.57 \%$ of the opportunities to access schools of high-quality would need to be rearranged to achieve equality of opportunity. In contrast, $5.94 \%$ of opportunities would need to be rearranged for schools of any quality. The HOI measure summarizes the opportunities for education, both in coverage and in the distribution among the groups, arising to 70.0 for admission to a school of any quality, but lowering to 58.6 for a school of high-quality.

\subsection{Determinants of Inequality: To Get an Offer from a High-Quality School}

The contributions of circumstances to the IOP is presented in the bottom part of Table 6 . Contributions represent the share of the D-index that is explained for each one of the circumstances. All the contributions add up to 100. Living in an attendance area where the school has high numbers of economically disadvantaged students (Title I school) was the most important factor affecting equality of opportunity in getting an offer to a middle school, which explains the $56 \%$ of the inequality measure for high-quality schools, and $35 \%$ for any quality schools.

The second factor was having a parent who is an employee at the school district, explaining about $10 \%$ of the measure. After that, the other two most important contributors to inequality in access are the SES level of the student (qualifying for FRL) (23\%) and being of black race/ethnicity (15\%), important only for high-quality schools.

\section{Discussion}

Goal 4 in the 2030 agenda for sustainable development [1] aims at ensuring inclusive and equitable quality education for all. The education 2030 framework for action recognizes the important role of education as the main driver of development [64]. It stresses the need to address all forms of exclusion 
and marginalization, to serve all learners, regardless of their context and personal characteristics, including "those from the poorest households, ethnic and linguistic minorities, indigenous people, and persons with special needs and disabilities." [64,65].

Equity issues constitute a major challenge in the achievement of the education goal [66]. Equality of educational opportunity specifies a fair way to distribute the available places, by giving all people the same chances for schooling. Governments are held responsible for designing a policy that equalizes educational opportunities. According to Dabalen et al. [8], a policy aiming at equitable access would require progress towards two objectives: first, expanding coverage, by ensuring that as many people as possible get the opportunities; and second, by allocating new opportunities first to the vulnerable population, those who are at a disadvantage due to their circumstances.

Using data from a large public urban school district in Florida, this work measures the opportunity to get access to high-quality education, i.e., how closely an existing admission policy matches the equality of opportunity principle. Two indicators of access to lower secondary education in magnet schools are assessed: whether the child is enrolled in a school; and whether the child has been admitted to a school. Since all kids that currently study in an SDHC magnet school had to go through the admission process at a previous point in time, enrollment reflects the long-term effect of the application of the admission policy in the past.

The coverage rate for the enrollment in SDHC magnet lower secondary high-quality schools is about $78 \%$. Worldwide the adjusted net enrollment rates reached $91 \%$ for primary education, $84 \%$ for lower secondary education and 63\% for upper secondary education in 2017 [66]. SDHC's access rate is close to the worldwide rate for children of the same age (only 6 points' difference), which is low considering that we accounted only for high-quality schools.

The D-index and the HOI measures indicate that all the students currently enrolled at SDHC magnet middle schools do not have the same opportunities to be well educated. The enrollment configuration at SDHC exposes that students with high socioeconomic status have a higher opportunity to get a high-quality education. Access is also distributed unevenly across children of different race/ethnicity: black children's share of the opportunity is below the overall coverage. Consistent with our findings, Burgess and Briggs [67] find that students from low-income families have around half the chance of attending high performing schools, compared to those from non-low-income families. This coverage rate is similar for public students at the middle level at SDHC (53.5\%) but significantly lower than the rate for magnet middle students in the district (77.7\%).

The allocation mechanism is important and determines how equal a society is in terms of an opportunity. Popular high performing schools are likely to be oversubscribed and school districts need to find ways to ensure an even social mix. One policy for the allocation of new educational opportunities, for instance, would be running a lottery where all kids have an equal chance of getting a place. A lottery mechanism is a way to achieve fairness in the assignment process [68]. Several school districts had examined the use of lotteries to allocate spots when oversubscribed [69-71].

If a person is a victim of bad circumstances, such as a displacement situation, or disability, then his/her opportunities would need to be relieved. In Roemer's viewpoint, individuals at disadvantage should receive more resources [6]. In such cases, a policy supporting preferential admissions for students of low socioeconomic status (or other criteria that identify kids in disadvantage) might be considered. SDHC is exploring weighted random allocation as a method for distributing school places fairly and for promoting a more even allocation of educational opportunities. When using weighted lotteries, some have slightly more chances than others, leveling the playing field for those in disadvantage. A measure to assess the level of equality in the allocation mechanism is needed.

The most statistically significant variables for the admission to high-quality schools at SDHC reveals efforts from the school district towards the equality goal. SDHC seems to be determined to help underprivileged children alleviate the personal circumstances, by assigning priority to those in disadvantage from their circumstances, such as living in poverty or residing in a neighborhood school with poor academic performance. This finding can be explained by the fact that school districts that 
accept Title I funds must offer school choice to students in public schools identified for improvement so that no student is trapped in an underperforming school [72]. Often schools implement this requirement allowing students at lagging schools to attend other schools in the district and giving priority to low achieving and low-income students.

Nevertheless, the socioeconomic status and the student's race/ethnicity seem to influence the chances of receiving an offer in high-quality schools, suggesting that those students might be at a disadvantage due to their personal or family circumstances. This result is consistent with our decomposition analysis that evidences that circumstances, the characteristics of the assigned area school, the socioeconomic status and students' race/ethnicity are the most significant contributors to IOP. Previous studies in Latin America reveal that the characteristics of the home (parents' education, the composition of the family) and its income account for the majority of inequalities in access to educational opportunities [38].

There are several methods for measuring equality, each with advantages and disadvantages, that can lead to different conclusions about the degree of inequality $[17,73]$. The analysis of IOP for access to lower secondary education of high quality performed in this study complements traditional inequality measures proposed for the SDG, such as PI. The parity index currently used in the SDG provides the relative magnitude of the disparity. Both, PI and the HOI, are indicators with a simple and clear interpretation and can be computed in a very transparent way. However, the HOI adds more insights than PI.

Three main contributions of HOI stand out: first, the HOI is a scalar synthetic measure of the gaps in access to basic services in multiple circumstances; in contrast, PI needs to be measured and analyzed for each circumstance independently; second, HOI summarizes the opportunities for education, both in coverage and in the distribution among the groups; in contrast, PI measures the relative access to education of one group versus the other group; there might be parity in access which yet masks other important inequalities, for instance when there are low levels of access for both groups; third, PI cannot easily be decomposed to show the sources of inequality; in contrast, the decomposition of the D-index allows the user to explore the marginal/average contribution of each circumstance to overall IOP.

An important caveat to interpreting our results is that we are only able to evaluate the influence of the children's circumstances in the admission from the set of applicants that were considered by the schools, i.e., those families who chose to apply to the lottery, but our findings may not generalize to other students. School choice is exercised in different ways by families. Better-educated parents make better-informed choices [63]. Previous studies have found that applicants take into consideration their social circumstances when stating their preferences for specialty schools [74]. SDHC does not have poverty level or race/ethnicity in the criteria for admission, yet both the criteria at the time of the decision on admission show relevance. Certain criteria might be important for the parents and not for the schools. Our analysis cannot isolate this effect.

While our study provides an important examination of how children circumstances influence the chances of school admission/enrollment, it involves some evident limitations. For instance, our analysis is a relatively static cross-sectional study in nature, allowing to compare many different variables at the same time, for a specific geographic area, for one academic year. Arguably, a superior assessment would consist of a longitudinal analysis to determine whether changes in the predictor variables predict changes in the characteristics of the students admitted to several school districts in a larger region, and over time. However, different school districts have different admission policies, and several observations of the same students over a period of time would be rare to find, due to the features of the data. It is our hope that, for the sake of transparency, as more admission data continues to be opened to researchers for more geographic areas over the next years, additional analysis can be conducted to better assess the dynamic aspects of the relationships examined by the present study. 


\section{Conclusions}

Prior research on educational opportunities measures how far a given distribution of individual outcomes is from equal opportunity, capturing different aspects of education, such as participation, attainment, and achievement. The aim of this paper is complementary to those contributions. Given the fact that the admission process is the earliest step in the education process, the main contribution of this study is in the assessment of the empirical distribution of the provision of opportunities for the admission to schools. Clear rules and priorities are set to ensure that the school allocation is fair: children with dissimilar backgrounds should all have equal access to good schools. This study attempts to measure the amount of "fairness" in such an initial allocation of scarce educational resources, from the beginning of the education process.

Our results indicate that the HOI metrics and the distribution of opportunities among different groups of children allow the identification and analysis of potential inequalities in access to education. $\mathrm{HOI}$ is capable of systematically monitoring and examining existing admission policy and identify potential inequality problems. Furthermore, the analysis of the contribution of each circumstance group can reveal admission criteria that have the potential to harm the educational opportunities for children.

By analyzing several school records of admission data, an equality of educational opportunity profile for a particular region produces actionable understandings that school district's policymakers can use to evaluate current admission policy, plan out its enrollment goals, make predictions of student enrollment, and optimize their resource allocation. This assessment should provide valuable insights into the capability of the indicators to reveal where policy intervention is necessary and supply points of view on how policy can be improved. In the future, these insights might help guide the design, development, and implementation of an effective public policy aimed at equalizing opportunity for access to high-quality education.

Author Contributions: Supervision, M.V.M.; Writing—original draft, L.M.P.; Writing—review \& editing, J.F. and J.A.V.

Funding: This research received no external funding.

Conflicts of Interest: The authors declare no conflict of interest.

\section{References}

1. United Nations General Assembly. Transforming Our World: The 2030 Agenda for Sustainable Development; No. A/RES/70/1; United Nations Development Program: New York, NY, USA, 2015.

2. UNESCO. Education for People and Planet: Creating Sustainable Futures for All, 2nd ed.; Global Education Monitoring Report; UNESCO Publishing: Paris, France, 2016.

3. World Bank. Learning to Realize Education's Promise; World Development Report 2018; World Bank: Washington, DC, USA, 2018.

4. World Bank. Atlas of Sustainable Development Goals 2018: From World Development Indicators; World Bank Atlas; World Bank: Washington, DC, USA, 2018.

5. IAEG-SDGs. “Tier Classification for Global SDG Indicators, 11 May 2018. 2018. Available online: https:/ / unstats.un. org/sdgs/iaeg-sdgs/tier-classification/ (accessed on 11 June 2018).

6. Roemer, J.E. Equality of Opportunity; Harvard University Press: Cambridge, MA, USA, 1998.

7. Barros, R.; Ferreira, F.H.G.; Vega, J.R.M.; Saavedra, J. Measuring Inequality of Opportunities in Latin America and the Caribbean; World Bank: Washington, DC, USA, 2009; p. 1152.

8. Dabalen, A.; Narayan, A.; Saavedra-Chanduvi, J.; Suarez, A.H.; Abras, A.; Tiwari, S. Do African Children Have an Equal Chance? A Human Opportunity Report for Sub-Saharan Africa; Directions in Development; World Bank: Washington, DC, USA, 2015.

9. Krishnan, N.; Ibarra, G.L.; Narayan, A.; Tiwari, S.; Vishwanath, T. Uneven Odds, Unequal Outcomes: Inequality of Opportunity in Middle East and North Africa; World Bank: Washington, DC, USA, 2016.

10. Vélez, C.E.; Azevedo, J.P.; Posso, C. Oportunidades Para los Niños Colombianos: Cuánto Avanzamos en Esta Década; Borradores de economía; Banco de la Republica: Bogota, Colombia, 2011. 
11. Kovacevic, M. Measurement of Inequality in Human Development: A Review; Human development research paper (HDRP); United Nations Development Programme: New York, NY, USA, 2010.

12. Shields, L.; Newman, A.; Satz, D. Equality of Educational Opportunity. In The Stanford Encyclopedia of Philosophy; Zalta, E.N., Ed.; Metaphysics Research Lab, Stanford University: Stanford, CA, USA, 2017.

13. Stiglitz, J. The Price of Inequality; W.W. Norton \& Company: New York, NY, USA, 2013.

14. Alvaredo, F.; Chancel, L.; Piketty, T.; Saez, E.; Zucman, G. World Inequality Report 2018; The Belknap Press of Harvard University Press: Cambridge, MA, USA, 2018.

15. Coleman, J.S.; Campbell, E.Q.; Hobson, C.J.; McPartland, J.; Mood, A.M.; Weinfeld, F.D.; York, R.L. Equality of Educational Opportunity. Biometrics 1967, 23, 163. [CrossRef]

16. PolicyLink and PERE. The National Equity Atlas, School Poverty Data. Available online: http:/ / nationalequityatlas. org/indicators/School_poverty (accessed on 21 August 2018).

17. IDS; ISSC; UNESCO. Challenging Inequalities: Pathways to a Just World; World Social Science Report; UNESCO Publishing: Paris, France, 2016.

18. OECD. Education at a Glance 2018: OECD Indicators; OECD Publishing: Paris, France, 2018.

19. Paes de Barros, R.P.; Vega, J.R.M.; Saavedra, J. Measuring Inequality of Opportunities for Children; World Bank: Washington, DC, USA, 2008.

20. Malczewski, J.; Jackson, M. Multicriteria spatial allocation of educational resources: An overview. Socio-Econ. Plan. Sci. 2000, 34, 219-235. [CrossRef]

21. Haan, M.D.; Gautier, P.; Oosterbeek, H.; Klaauw, B.V.D. The Performance of School Assignment Mechanisms in Practice; Centre for Economic Policy Research: London, UK, 2015.

22. Balinski, M.; Sönmez, T. A Tale of Two Mechanisms: Student Placement. J. Econ. Theory 1999, 84, 73-94. [CrossRef]

23. Abdulkadiroğlu, A.; Pathak, P.A.; Roth, A.E. The New York City High School Match. Am. Econ. Rev. 2005, 95, 364-367. [CrossRef]

24. Abdulkadiroğlu, A.; Pathak, P.A.; Roth, A.E.; Sönmez, T. The Boston Public School Match. Am. Econ. Rev. 2005, 95, 368-371. [CrossRef]

25. Pathak, P.A.; Sönmez, T. School Admissions Reform in Chicago and England: Comparing Mechanisms by their Vulnerability to Manipulation. Am. Econ. Rev. 2013, 103, 80-106. [CrossRef]

26. Kojima, F.; Ünver, M.U. The Boston school-choice mechanism: An axiomatic approach. Econ. Theory 2014, 55, 515-544. [CrossRef]

27. Carrasco, A.; Gutiérrez, G.; Flores, C. Failed regulations and school composition: Selective admission practices in Chilean primary schools. J. Educ. Policy 2017, 32, 642-672. [CrossRef]

28. Lubienski, C.; Gulosino, C.; Weitzel, P. School choice and competitive incentives: Mapping the distribution of educational opportunities across local education markets. Am. J. Educ. 2009, 115, 601-647. [CrossRef]

29. Dur, U.; Hammond, R.; Morrill, T.; Evans, L.P.; Carroza, G. “Identifying the harm of manipulable school-choice mechanisms. Am. Econ. J. Econ. Policy 2018, 10, 187-213. [CrossRef]

30. Calsamiglia, C.; Güell, M. The Illusion of School Choice: Empirical Evidence from Barcelona; Working Paper No. 712; Research Group, Federal Reserve Bank of Minneapolis: Minneapolis, MN, USA, 2014.

31. NCES and U.S. Department of Education. Common Core of Data (CCD). Available online: https:/ / nces.ed.gov/ ccd/ccddata.asp (accessed on 8 March 2018).

32. Groulx, T. Influences of segregation and desegregation on the bands at historically black high schools of Hillsborough County, Florida. J. Hist. Res. Music Educ. 2014, 37, 129-149. [CrossRef]

33. Shircliffe, B.J. Desegregation and the historically black high school: The establishment of Howard W. Blake in Tampa, Florida. Urban Rev. 2009, 34, 135-158. [CrossRef]

34. Borman, K.M.; Eitle, T.; Eitle, D.J.; Lee, R.; Johnson, L.; Cobb-Roberts, D.; Dorn, S.; Shircliffe, B. Accountability in a post-desegregation era: The continuing significance of racial segregation in Florida's schools. Am. Educ. Res. J. 2012, 41, 605-631. [CrossRef]

35. Taylor, K.; Phillips, K.; Goldring, E. Latino Parents' choice of Magnet school: How school choice differs across racial and ethnic boundaries. Educ. Urban Soc. 2010, 42, 758-789. [CrossRef]

36. FDOE. Guide to Calculating School and District Grades; FDOE: Tallahassee, FL, USA, 2018; p. 36.

37. OECD. Education at a Glance 2017: OECD Indicators; OECD: Paris, France, 2017.

38. Molinas, J.R.; Paes de Barros, R.P.; Saavedra, J.; Giugale, M. Do Our Children Have a Chance? The 2010 Human Opportunity Report for Latin America and the Caribbean; The World Bank: Washington, DC, USA, 2012. 
39. Ferreira, F.; Gignoux, J. The Measurement of Educational Inequality: Achievement and Opportunity. World Bank Econ. Rev. 2014, 28, 210-246. [CrossRef]

40. NCES. Monitoring School Quality: An Indicators Report; U.S. Department of Education, National Center of Education Statistics (NCES): Washington, DC, USA, 2010.

41. Ferreira, F.H.G.; Gignoux, J.R.M. The measurement of inequality of Opportunity: Theory and applications to Latin America. Rev. Income Wealth 2011, 57, 622-657. [CrossRef]

42. Ferreira, F.H.G.; Gignoux, J. Inequality of Opportunity for Education: The Case of Turkey; No. Working Paper Number 4; The World Bank: Ankara, Turkey, 2010.

43. Paes de Barros, R.; Ferreira, F.H.G.; Vega, J.R.M.; Saavedra, J. Midiendo la desigualdad de oportunidades en America Latina y el Caribe; World Bank: Washington, DC, USA, 2009; p. 1152.

44. Paes de Barros, R.P.; Vega, J.R.M.; Saavedra, J. Measuring progress toward basic opportunities for all. Braz. Rev. Econom. 2010, 30, 335-367. [CrossRef]

45. Azevedo, J.P.; Franco, S.; Rubiano, E.; Hoyos, A. HOI: Stata module to compute the Human Opportunity Index," in Statistical Software Components; S457191; Boston College Department of Economics: Chestnut Hill, MA, USA, 2010.

46. Juarez, F.W.C.; Soloaga, I. IOP: Stata Module to Compute Different Measures of Inequality of Opportunity for Dichotomous, Ordered, and Continuous Outcome Variables; S457442; Boston College Department of Economics: Chestnut Hill, MA, USA, 2014.

47. Soloaga, I.; Juarez, F.W.C. IOP: Estimar desigualdad de oportunidades cuando el indicador es binario. In Aplicaciones en Economía y Ciencias Sociales Con Stata; Mendoza-Velázquez, A., Ed.; Stata Press: College Station, TX, USA, 2013.

48. Shorrocks, A.F. Decomposition Procedures for Distributional Analysis: A Unified Framework based on the Shapley Value; University of Essex: Essex, UK, 1999.

49. Hoyos, A. HOISHAPLEY: Stata module to decompose the Human Opportunity Index. In Statistical Software Components; S457618; Boston College Department of Economics: Chestnut Hill, MA, USA, 2013.

50. Roemer, J.E.; Trannoy, A. Equality of Opportunity: Theory and Measurement. J. Econ. Lit. 2016, 54, 1288-1332. [CrossRef]

51. Ramos, X.; van de Gaer, D. Approaches to Inequality of Opportunity: Principles, measures and evidence. J. Econ. Surv. 2016, 30, 855-883. [CrossRef]

52. Schlicht, R.; Stadelmann-Steffen, I.; Freitag, M. Educational Inequality in the EU: The Effectiveness of the National Education Policy. Eur. Union Politics 2016, 11, 29-59. [CrossRef]

53. Schmidt, W.; Cogan, L.; Houang, R.; McKnight, C. Equality of Education Opportunity: Myth or Reality in US Schooling; The Education Policy Center at Michigan State University: East Lansing, MI, USA, 2011.

54. Escobal, J.; Saavedra, J.; Vakis, R. Está el Piso Parejo Para los Niños en el Perú?: Medición y Comprensión de la Evolución de Las Oportunidades; World Bank: Washington, DC, USA, 2012.

55. Bourguignon, F.O.; Ferreira, F.; Menéndez, M. Inequality of Opportunity in Brazil. Rev. Income Wealth 2007, 53, 585-618. [CrossRef]

56. Vélez, C.E.; Al-Shawarby, S.; El-Laithy, H. Equality of Opportunity for Children in Egypt 2000-2009: Achievements and Challenges; Policy Research Working Paper; World Bank: Washington, DC, USA, 2012.

57. Thai, N.T.K.; Thu, V.T. Opportunities for Children in Vietnam; Policy Research Working Series; World Bank: Washington, DC, USA, 2015.

58. Picard, N.; Wolff, F.O.C. Measuring educational inequalities: A method and an application to Albania. J. Popul. Econ. 2007, 23, 989-1023. [CrossRef]

59. Cuesta, J.; Abras, A. Education and equal opportunities among Liberian children. J. Econ. Policy Reform 2013, 16, 237-258. [CrossRef]

60. Llambí, C.; Perera, M.; Messina, P. Desigualdad de Oportunidades y el Rol Del Sistema Educativo en Los Logros de Los Jóvenes Uruguayos; Centro de Investigaciones Económicas-CINVE: Montevideo, Uruguay, 2009.

61. UNESCO. World Inequality Database on Education (WIDE). Available online: https://www.education-inequalities. org/ (accessed on 22 October 2018).

62. UNESCO Institute for Statistics (UIS). Handbook on Measuring Equity in Education; UNESCO Institute for Statistics (UIS): Montreal, QC, Canada, 2018.

63. Musset, P. School Choice and Equity: Current Policies in OECD Countries and a Literature Review; OECD Education Working Papers No. 66; OECD Publishing: Paris, France, 2012; p. 51.

64. UNESCO. Education 2030: Incheon Declaration and Framework for Action for the Implementation of Sustainable Development Goal 4; World Education Forum 2015: Incheon, Korea, 2015. 
65. UNESCO. A Guide for Ensuring Inclusion and Equity in Education; UNESCO: Paris, France, 2017.

66. United Nations. Progress Towards the Sustainable Development Goals: Report of the Secretary-General; United Nations: San Francisco, CA, USA, 2017.

67. Burgess, S.; Briggs, A. School assignment, school choice and social mobility. Econ. Educ. Rev. 2009, 29, 39-649. [CrossRef]

68. Pathak, P.A.; Sethuraman, J. Lotteries in Student Assignment: An Equivalence Result; NBER Working Papers; Working Paper 16140; National Bureau of Economic Research: Cambridge, MA, USA, 2010. [CrossRef]

69. Dur, S.U.; Duke, K.; Pathak, P.A.; Tayfun, S. Priorities vs. Precedence in School Choice: Theory and Evidence from Boston. Semin. Ser. GSB Econ. 2013. Available online: https://economics.stanford.edu/content/tba-39 (accessed on 8 November 2018).

70. Cullen, J.B.; Jacob, B.A.; Levitt, S. The Effect of School Choice on Student Outcomes: Evidence from Randomized Lotteries; NBER Working Paper Series; Working Paper 10113; National Bureau of Economic Research: Cambridge, MA, USA, 2003. [CrossRef]

71. Stasz, C.; von Stolk, C.; Europe, R.; Rand, C.; Sutton, T.W. The Use of Lottery Systems in School Admissions; RAND Working Papers; RAND: Santa Monica, CA, USA, 2007.

72. DOE. A Guide to Education and no Child left Behind; U.S. Department of Education: Washington, DC, USA, 2004.

73. UIS. Global Education Digest 2010: Comparing Education Statistics Across the World; Unesco Institute for Statistics: Montreal, QC, Canada, 2010.

74. Prieto, L.M.; Aguero-Valverde, J.; Zarrate-Cardenas, G.; van Maarseveen, M. Parental preferences in the choice for a specialty school. J. Sch. Choice 2018, 1-30. [CrossRef]

(C) 2018 by the authors. Licensee MDPI, Basel, Switzerland. This article is an open access article distributed under the terms and conditions of the Creative Commons Attribution (CC BY) license (http:/ / creativecommons.org/licenses/by/4.0/). 